\title{
Journeying into Academia via Immersion into Qualitative Research: Professor Shaffir as a Master Guide
}

\author{
Efa E. Etoroma \\ Concordia University of Edmonton, Canada
}

DOI: http://dx.doi.org/10.18778/1733-8077.16.2.05

Keywords:

Academia; Immersion;

Validity; Research;

Shaffir

\begin{abstract}
The choice of a work career is one of the most important events in a person's life course and typically involves secondary socialization and identification with role models. This paper is concerned with the crucial role of my PhD dissertation supervisor at McMaster University, Dr. Billy Shaffir, in my choice of an academic career. I highlight and celebrate how, through the guidance of Dr. Shaffir, I experienced "immersive socialization" into field research and happily converted from an intended business career to an academic career.
\end{abstract}

Efa E. Etoroma holds a PhD degree from McMaster University in Hamilton, Ontario, Canada and is an Associate Professor of Sociology at Concordia University of Edmonton in Edmonton, Alberta, Canada. Nigerian born, Efa moved to Canada in 1978 and has lived in the provinces of Manitoba, Nova Scotia, Ontario, British Columbia, and Alberta. Efa has published on aspects of Black life in Canada and his current research interests include autoethnography, Black community building in Canada, and the social psychology of identity transformation among Blacks in Canada.

email address: efa.etoroma@concordia.ab.ca

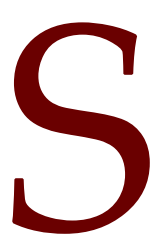
tudies of the life course tend to focus on at least one of the following three issues: careers, identity and self-esteem, and stress and satisfaction (DeLamater, Myers, and Collett 2015:99). This paper deals with the issue of "careers," by which is meant a "sequence of roleseach with its own set of activities-that a person enacts during his or her lifetime" (DeLamater et al. 2015:99). This paper outlines how my PhD dissertation supervisor, Dr. Billy Shaffir, influenced my choice of an academic career by providing me with a sense of safety while encouraging me to immerse myself into field research. My focus will be on how 
Dr. Shaffir helped me navigate through the thorniest area of my dissertation research: my struggles with issues of validity.

In order to contextualize the impact of Dr. Shaffir's influence on my career choice, I shall first retrace my gradual movement towards an academic career, outlining some biographical reasons why a career in academia seemed rather improbable for me. Next, I shall discuss my immersion into qualitative sociological research and how navigating the issues of validity helped launch me into an academic career.

\section{My Reluctant Journey towards Academia}

When I was growing up in Nigeria, the thought of becoming an academic did not even enter my mind. I fully expected to attend university and meet professors there, but I never even dreamed of or desired to become a professor. For one thing, I had some well mapped out career paths: my parents wanted me to become a business executive, such as a bank manager, and I wanted to become a journalist. Besides, since there were no universities in any towns where I grew up, I had no role models who were professors. Up till 1978 when I moved from Warri, Nigeria to Winnipeg, Canada as an International Student to study Business Administration at Success Commercial College, the only professor I met in person was a friend's uncle.

After successfully completing my business administration diploma program, I enrolled as a first-year undergraduate student at Dalhousie University in Halifax, Nova Scotia. My goal was to work towards obtaining an MBA degree in Canada, and some friends encouraged me to join them at Dalhousie University in Halifax, which I gladly did.
Although I liked Dalhousie University, I decided to move out of the city because the high cost of living, exacerbated by the high differential fees imposed on international students, made living in Halifax economically unbearable. I left Dalhousie University for the University of Manitoba (U of M) in Winnipeg in the spring of 1980. $\mathrm{U}$ of $\mathrm{M}$ did not have a differential fee system, and the cost of living in Winnipeg was significantly less than was the case in Halifax.

In the spring of 1982, I graduated with a three-year BA degree in sociology from U of M. Since I held a three-year degree, I was required to do an extra year of "Pre-Masters" courses before officially being considered an MA degree student. By early 1984, my thesis entitled "The Educational and Occupational Expectations and Aspirations of High School Students in Winnipeg," seemed to be on schedule.

To my utter surprise, just as I was arranging for an August 1984 one-way plane ticket to Nigeria, I heard rumors that my thesis supervisor was on her way out of the university. These rumors turned out to be true. My thesis supervisor left U of M in 1984. The rather sudden departure of my thesis supervisor left me in a quagmire. I realized that completing my MA degree on schedule was out of the question; I even had some doubts as to whether I would complete a graduate degree in Canada. Thankfully, in the summer of 1985, with the able guidance of a new committee and a new thesis supervisor, the late Dr. Larry Douglas, I successfully completed my MA degree program at $\mathrm{U}$ of $\mathrm{M}$ with a thesis entitled, "The Socio-Historical Analysis of Military Intervention in Nigerian Politics"' (Etoroma 1985).

After obtaining my MA degree, I mailed the parchment to my dad in Nigeria and assured him that I still intended to obtain an MBA degree and that 
graduate degrees in sociology would give me some advantages in the corporate world. Dad gave me his blessings. In the fall of 1985, I enrolled in the PhD program at the University of Calgary ( $U$ of $C$ ) where I was assigned the position of Teaching Assistant for a course on Quantitative Methods and Social Statistics, a position that I accepted very reluctantly. Thus, I went from completing a thesis based on historical methods at $\mathrm{U}$ of $\mathrm{M}$ to assisting students with quantitative methods-based assignments at $\mathrm{U}$ of $\mathrm{C}$. I felt so out of place at $U$ of $C$ that, within a few months of enrolling there, I started looking for a different academic environment.

I transferred from U of C to McMaster University in the fall of 1986. Although I was committed to obtaining a PhD degree, my goal was to be a professional documentary maker and not an academic. I cherished the work of Canada's National Film Board (NFB) and had a desire to be involved with such an organization. I applied to McMaster because I liked its program, since it emphasized research/dissertation over course-work. My goal was to conduct a socio-historical study of the dilemmas of military disengagement in African politics. Based on the credits I received for coursework done at $\mathrm{U}$ of $\mathrm{C}$, I was required to take only two courses at McMaster: Quantitative Methods with Dr. Alfred Hunter and Qualitative Methods with Dr. Billy Shaffir.

\section{The Thrills of Immersion}

I first met Dr. William Shaffir in the 1986/87 academic year when I was a student in Sociology 742, his graduate level Qualitative Methods course. Since I was new to McMaster University, I did what most new students did: I asked other students for their opinions of both the professor and the course. The consensus on Dr. Shaffir was as follows: (a) he will get you doing field research right off the bat, (b) he is very approachable, (c) he will tell you lots of stories about his research on "ultra-ultra-orthodox Jews," (d) he will tell you lots of stories about Montreal, and (e) he will get you connected with his friends and colleagues in academia.

I found all of the opinions above to be pleasantly true. I liked the challenge of the Qualitative Methods course because it seemed to be in line with my long-standing interest in journalism, promised to be quite informal, and promised to be a gateway to a wide variety of career options. Given my background as a young man struggling to discover his career path while trying to respect the wishes of his African parents who had sacrificed enormously to send him abroad, any heavy-handed attempts to force me into a career labyrinth would have been counter-productive. I needed options in my life, and both the Qualitative Methods course and Dr. Shaffir seemed structured to provide me with what I needed.

While at $\mathrm{U}$ of $\mathrm{M} I \mathrm{had}$ acquired some knowledge of field research-particularly through a second-year undergraduate course in sociological methods. But, my first immersion into field research was in connection with Dr. Shaffir's Sociology 742 course. The following excerpt from the Fall 2017 syllabus for the Sociology 742 course captures the essence of the course:

This course is organized around problems of doing field research. Many of our discussions will focus on the practical problems confronting the researcher. The seminar will serve as a venue for participants to share their field experiences and consider the processes by which field research is accomplished. 
The seminar is organized informally and driven, largely, by the kinds of projects that students undertake. In addition, readings are assigned and will serve as a basis for discussion.

As important as this reading material may be for learning about field research, however, it is not a substitute for being actively engaged in the field.

There are two course requirements. First, each student is expected to initiate a project using field research methods, and will submit field notes regularly...Second, you will be required to submit a paper based on your chosen research, to constitute the remaining portion of the final grade. [Shaffir 2017]

Dr. Shaffir told the Fall 1986 Sociology 742 class that he would show us the ropes, but that the best way for us to learn field research was to do field research. The point was for each student to be immersed into a local ethno-cultural or religious community, beginning with a major organization such as a church or a provisionary store.

What was it like to learn field research by doing field research? A cogent analogy is Richard J. Foster's (2011:133) point about meditation: "Thomas Merton rightly observed, 'You cannot learn meditation from a book. You have to meditate.'... the purpose of any book on meditation is to get us into the practice of meditation just like a book on the rules for the game of soccer is intended to get us out on the field and into the game."

Another analogy can be seen in Sidney Poitier's (2000:34) autobiography, The Measure of a Man, where he recounts the following story about learning to swim:

Cat Island is forty-six miles long and three miles wide, and even as a small child I was free to roam anywhere. I would even go in sometimes and swim by myself. I had the confidence, because when I was very small, my mother threw me in the ocean and watched without moving as I struggled to survive... She watched as the ocean swallowed me, second by second. Then, mercifully, my father's hands reached under, fished me out, and handed me back to my mother...who threw me back in again, and again, until she was convinced that I knew how to swim.

In qualitative research, immersion invariably involves acceptance by one's study group. As Wax (1978:258) puts it, “Immersion or stepping into, or becoming a member of, a society or culture or living people is always a joint process, involving numerous accommodations and adjustments by both the fieldworker and the people who 'accept' him." Immersion is typically time-consuming as it involves a detailed examination of one's data-that is, study group, archival materials, et cetera (Borkan 1999). Thus, it is important for the researcher to be prudent in his or her allocation of resources. Immersion is a process that acknowledges and treasures the independence of each actor while providing experienced guides to prevent actors from running into destructive situations or problems.

Given my rocky journey towards and within academia, I was enamored by the opportunity of exercising the freedoms that an immersion experience would offer me. Particularly in terms of immersion in one's study, I was very intrigued by Dr. Shaffir's discussions of his research of Hassidic Jews, and I wanted to do a similar study. However, since I was new to Hamilton in 1986, I was confronted with a major obstacle: I did not know the city's communities well. Thankfully, based on both Dr. Shaffir's encouraging statements about ethnic religious communities and my experiences in Winnipeg, Halifax, 
and Calgary, I decided that a Black church was an appropriate place to begin my study of Hamilton's Black community.

My acquaintances at McMaster University, most of whom were White, were familiar with and directed me to Hamilton's oldest Black church: Stewart Memorial Church (SMC) which was founded in 1835 by Reverend Josiah Henson. SMC has maintained vestiges of the practices of its original congregants who arrived in Hamilton via the Underground Railroad; thus, for example, old-fashioned plantation spirituals are still sung during regular church services.

When I phoned the church office and indicated my intention of studying a Black group in Hamilton, SMC's assistant pastor, Reverend Robert Foster, expressed his interest in the work and offered me rides to and from the church. These trips were very beneficial for me since they offered me opportunities to interact informally with Reverend Foster, who, in turn, used them as opportunities to introduce me to some of the neighborhoods where Black Hamiltonians once lived. In short, my study of SMC launched me into a field research of Hamilton's Black community and, ultimately, helped to anchor me in that community. By doing field research within Hamilton's Black community, I gained access to Black churches and to virtually every other significant segment of Hamilton's and, indeed, Canada's Black community.

After completing my PhD course requirements, I decided to pursue writing a dissertation on Black community building in Hamilton. I had enrolled at McMaster with a chip on my shoulder that was later reinforced by my reading of Wilfred Cude's (1987) book, The PhD Trap. Based on his negative experiences as a doctoral candidate in a humanities program at the University of Alberta in Edmonton, Cude wrote his book about what he saw as structural problems in many North American $\mathrm{PhD}$ programs. By the time I started working on my dissertation, my mindset was such that an authoritarian style of leadership would have derailed my academic pursuits.

Given my positive experience with Dr. Shaffir and with his Sociology 742 course, I decided to approach Dr. Shaffir about the feasibility of having him as the supervisor for my $\mathrm{PhD}$ dissertation. I was thrilled that Dr. Shaffir granted my request. I, therefore, began my dissertation research by building intensely on my SMC study. After studying SMC, I studied each of the other Black churches in Hamilton. I then studied local Black businesses, such as provisionary stores and barber shops, and Black national organizations such as the Jamaican Association and the Ghanaian Association (Etoroma 1992).

Dr. Shaffir's masterful application of the philosophy of learning field research by doing field research manifested itself in many ways as I studied the Black community. One pleasant memory for me was when I informed Dr. Shaffir that Hamilton's Black churches were so different from one another that I could not find any particular ways in which these churches taught congregants about the Black experience. Dr. Shaffir referred me to his own research and pointed out that socialization is often passive. With time, I saw passive socialization at work in Black churches, homes, and other spaces in the form of photographs and other expressions of material culture; for example, SMC had a photograph of Lincoln Alexander, a Black man who was Ontario's Lieutenant Governor from 1985 to 1991, prominently displayed in its main sanctuary. 


\section{The Thorny Side of Immersion: How Combating Issues of Validity Led to an Academic Career}

In retrospect, my work towards a $\mathrm{PhD}$ degree was almost derailed by my doubts about whether my research was truly scholarly. I was particularly beset with the psychological burden of attempting to maintain the necessary distance from my subject matter. Primarily as a Black person studying fellow Blacks, I did not see how I could minimize the potential threats to the validity of my data; I was particularly concerned about the potential of "going native." Although I was studying my own community, my work was a legitimate form of autoethnographic research (Holt 2003:20); the problem was that I had debilitating concerns borne of ignorance.

When I discussed my concerns with Dr. Shaffir, he assured me that while my consternations were legitimate, they were readily solvable. Dr. Shaffir provided me with two categories of responses to my concerns: (a) even though I am a Black man studying the Black community, as long as I am doing my research, I will likely be, at best, a "marginal native" within the Black community and (b) there are steps I need to take in order to minimize potential threats to validity.

Concerning the matter of being a "marginal native," Freilich (1970:2) contends that field researchers' involvement in study groups range on a continuum from "privileged stranger" to "native." The "privileged stranger" has only instrumental membership in the study group in the sense that $\mathrm{s} /$ he participates in the study group to some extent, but is also allowed the privilege of interviewing group members and recording what s/he observes (Freilich 1970:2). In contrast, the "native" behaves and thinks in ways that approximate those of the study group. Freilich (1970:2) contends that regardless of the role assumed, the fieldworker is invariably "a marginal man in the community, an outsider."

According to Wax (1978), even if the researcher is accepted into an ethnic group, s/he would invariably remain as what may be variously referred to as a non-native, an outsider, or a stranger. As such, the only type of membership available to the researcher is "attached" or "instrumental" membership. Such a member is "a person who, though he always is and remains an outsider or non-native, may function in the society in a manner that is useful and agreeable to his hosts" (Wax 1978:264). Wax further notes that, unlike newcomers to a group, the field researcher is generally not socialized into a pre-existing role; rather s/he must continually team up with the group in inventing suitable roles (Wax 1978:266).

Regarding the matter of minimizing potential issues of validity, McCall and Simmons (1969:78) classified into three categories the sources of threats to the validity and reliability of field research:

1. reactive effects of the observer's presence or activities on the phenomena being observed;

2. distorting effects of selective perception and interpretation on the observer's part; and

3. limitations on the observer's ability to witness all relevant aspects of the phenomena in question.

Since the most problematic of these threats for me was "distorting effects," I shall focus the bulk of the discussion below on how, under the guidance of Dr. Shaffir, I successfully dealt with distorting effects. Moreover, in order to highlight the conse- 
quences of subduing "distorting effects" on my eventual career choice, I shall save my discussion of these effects for last; I shall first discuss "reactive effects" and "observer effects."

In general, two factors helped to minimize the potential "reactive effects" of my presence on my study groups. First, in spite of my efforts to broadcast my identity as a researcher to members of the study groups, my identity was known by only a small minority of the members of these groups. Lofland and Lofland (1984:24) contend that regardless of the researcher's wishes, "all research is secret to some degree because the people under study do not always remember that the researcher is a researcher." Another way in which I minimized reactive effects was by remaining long enough in the field. For, with time, group members are likely either not to notice the researcher's presence or not take it into account (Becker 1970:43-44).

A major way in which "observer effects" were minimized was by playing back observations to various Black Hamiltonians in either verbal or written form (Shaffir, Stebbins, and Turowetz 1980:14). I made a habit of playing back findings to members of the Black community, partly because some interviewees requested these findings as a condition for offering any further information. Quite crucially in the context of "observer effects," my status as a researcher generally made me only a marginal member of the study groups. I did not formally join any local Black organization, because I believed that, particularly because I am Black, membership in any of these organizations would undermine my desire to be insulated from the very probable factionalisms existent within the community. Since I did not become a formal member of any local Black organization, my socialization into roles within the various groups I studied was necessarily different from that of new members. For example, I was never assigned any formal duties; whenever I was asked to do anything, members stressed that I was only "helping" and that had group membership been greater, they would not have "bothered" me with any work (see: Adler and Adler 1987:41).

"Distorting effects" refer to the fact that researchers' perception and interpretation of phenomena are typically selective. Observer-based distorting effects, including the threat of "going native," are typically minimized by taking what Posner (1980:209) refers to as a "psychic breathing space"; that is, leaving the field, every now and then.

Dealing with distorting effects was quite problematic for me, for it was virtually impossible for me to distance myself from the Black community for any length of time. Even when I decided not to attend any events organized by or in relation to Blacks in Hamilton, some friends and acquaintances would meet me at home or at the university and offer details concerning these events. Given my predicament, I could imagine only one viable way of avoiding the problem of "going native": although I always welcomed information about the Black community, I sometimes did not read the materials brought to my attention for a week or longer.

Ultimately, distance from the Hamilton Black community was achieved when I moved out of the province of Ontario in the spring of 1991. Dr. Shaffir agreed to give me his blessings to move out of province on the condition that I commit to keeping in contact via email and regular mail. When I moved out of the province of Ontario, I became a de facto long-distance student. It is a great testament to the high regard in which Dr. Shaffir is held by his peers that sociologists at both the University of Manitoba 
and the University of Alberta gladly provided me with Internet access when I introduced myself as one of Dr. Shaffir's graduate students.

Perhaps the most beneficial "psychic breathing space" for me was the opportunity of teaching a handful of courses. My first teaching opportunity was in the 1990/91 academic year when I taught off-campus evening courses at both McMaster and Wilfrid Laurier universities. It is precisely in regard to using teaching opportunities as buffers against "going native" that I owe Dr. Shaffir special gratitude. Dr. Shaffir encouraged me to and, indeed, expressly approved my foray into teaching, with the proviso that I provide him with evidence of progress in my research endeavors. The flexibility that Dr. Shaffir offered me was far more than I deemed possible in my originally intended career of banking. Furthermore, teaching helped me cultivate positive relationships with my students and allowed me to experience profound satisfaction in seeing my students thrive from the feedback they receive from me.

I ventured into teaching armed with an age-old Talmudic lesson I had seen exemplified by Dr. Shaffir: rebuff students with your weaker hand and draw them to yourself with your stronger hand. This is the balancing act of teaching as outlined in Sotah 47a:6 of the online William Davidson Talmud (2019): "The Sages taught: It should always be the left, weaker, hand that pushes another away and the right, stronger, hand that draws him near. In other words, even when a student is rebuffed, he should be given the opportunity to return."

\section{Conclusion}

Given my background, it is rather surprising that I have spent more than two and half decades teaching sociology full-time. I believe one of the most crucial things that prepared me for my vocation as a sociology professor is the way in which Dr. Shaffir guided me through issues of validity in my $\mathrm{PhD}$ dissertation research. In particular, I believe that by permitting me to use off-campus teaching as a "psychic breathing space" militating against validity issues, Dr. Shaffir effectively helped me experience the contagious joys of an academic career. Teaching opportunities provided me with the space I needed in order to see my research endeavors with new eyes; these opportunities also provided me with needed finances and kindled my interest in teaching. I found earning a living as a university instructor so rewarding that I knew I had found my vocational calling.

\section{References}

Adler, Patricia A. and Peter Adler. 1987. Membership Roles in Field Research. Newbury Park, CA: Sage Publications.

Becker, Howard S.1970. Sociological Work: Method and Substance. Chicago: Aldine.

Borkan, Jeffrey.1999. “Immersion/Crystallization." Pp. 179194 in Doing Qualitative Research, edited by B. F. Crabtree and W. L. Miller. Thousand Oaks, CA: Sage Publications.
Cude, William.1987. The PhD Trap. West Bay, NS: Medicine Label Press.

DeLamater, John, Daniel J. Myers, and Jessica L. Collett. 2015. Social Psychology. Boulder, CO: Westview Press.

Etoroma, Efajemue. 1985. "The Socio-Historical Foundations of Military Intervention in Nigerian Politics." M.A. Thesis, Department of Sociology, University of Manitoba, Winnipeg, MB, Canada. 
Etoroma, Efajemue. 1992. "Blacks in Hamilton: An Analysis of Factors in Community Building." PhD Thesis. Department of Sociology, McMaster University, Hamilton, Ontario, Canada.

Foster, Richard J. 2011. Sanctuary of the Soul: A Journey into Meditative Prayer. Downers Grove, IL: IVP Books.

Freilich, Morris. 1970. “Field Work: An Introduction.” Pp. 1-38 in Marginal Natives: Anthropologists at Work, edited by M. Freilich. New York: Harper and Row.

Holt, Nicholas. 2003. "Representation, Legitimation, and Autoethnography: An Autoethnographic Writing Story." International Journal of Qualitative Methods 2(1):18-28.

Lofland, John and Lyn H. Lofland. 1984. Analyzing Social Settings: A Guide to Qualitative Observation and Analysis. Belmont, CA: Wadsworth Publishing.

McCall, George J. and Jerry L. Simmons (eds.). 1969. Issues in Participant Observation: A Text and Reader. Reading, MA: Addison-Wesley.
Poitier, Sidney. 2000. The Measure of a Man: A Spiritual Autobiography. New York: Harper Collins Publishers.

Posner, Judith. 1980. “Urban Anthropology: Fieldwork in Semifamiliar Settings." Pp. 203-211 in Fieldwork Experience, edited by W. B. Shaffir, R. A. Stebbins, and A. Turowetz. New York: St. Martin's Press.

Shaffir, William. 2017. “Sociology 742 Outline.” Retrieved March 09, 2019 (https://sociology.mcmaster.ca/courses/qualitative-methods/active-outline/@@display-file/outline_file/742_WS_F17.pdf).

Shaffir, William B., Robert A. Stebbins, and Allan Turowetz (eds.). 1980. Fieldwork Experience: Qualitative Approaches to Social Research. New York: St. Martin's Press.

Wax, Rosalie. 1978. "The Ambiguities of Fieldwork." Pp. 258268 in Sociological Methods: A Sourcebook, edited by N. K. Denzin. Seattle, WA: McGraw-Hill.

William Davidson Talmud. 2019. Retrieved March 09, 2019 (https:// www.sefaria.org/Sotah.47a.6?lang=bi\&with=all\&lang2=bi).

\section{Citation}

Etoroma, Efa E. 2020. “Journeying into Academia via Immersion into Qualitative Research: Professor Shaffir as a Master Guide.” Qualitative Sociology Review 16(2):52-60. Retrieved Month, Year (http://www.qualitativesociologyreview.org/ENG/archive_eng. php). DOI: http://dx.doi.org/10.18778/1733-8077.16.2.05 